DEPARTAMENTO DE ANATOMIA DESCRITIVA DOS ANIMAIS DOMESTICOS

Diretor: Prof. Dr. Orlando M. Palva

\title{
COMPORTAMENTO DA ANSA SPIRALIS DO COLON, EM BCFALOS (BUBALUS BUBALIS - LINNAEUS, 1758)
}

\author{
(THE ARRANGEMENT OF THE ANSA SPIRALIS
}

OF THE BUFFALO COLON )

JOSE PEDUTI NETO

Prof. Assistente
ANTONIO FERNANDES FILHO

Prof. Assistente Doutor

\begin{abstract}
I. L. DE SANTIS PRADA
Pror. Asslstente Doutor
\end{abstract}

\section{INTRODUÇÃO}

O comportamento da ansa spiralis, uma das três porções do colon primum, homólogo do colon ascendens do homem (SUSSDORF - 1901; MARTIN - 1912; ZIETZSCHMANN - 1925; KRÜGER - 1929), recentemente analisado em búfalos Jaffarabadi (PEDUTI, BORELLI \& BOCALLETTI - 1969), é, agora, examinado em exemplares dessa espécie, sem raça definida. Buscamos apurar, dêste modo, eventual influência da variável em questão, visto PEDUTI, BORELLI \& BOCALLETTI, já terem analisado o aludido volteamento frente a outros fatores, atestando assim, ao contrário do sugerido por KOLDA (1931) para caprinos e ovinos, a não interferência da idade, bem como do sexo, no comportamento das espiras nos animais estudados. Devemos ainda levar em conta a quase total ausência, na literatura a nosso alcance, de informes relativos ao citado segmento intestinal em bubalinos, pois, afora a mencionada pesquisa, dados de caráter genérico são fornecidos apenas por GIROLAMO (1950) que, sem detalhar número, raça, idade e sexo dos espécimes utilizados, registra, para a alça espiral, dois giros centrípetos e dois centrífugos ou, excepcionalmente, três, em ambos os sentidos. Por sua vez, PEDUTI, BORELLI \& BOCALLETTI, no já referido estudo, dentre as 51 peças pertencentes a adultos (14 machos e 37 fêmeas) anotam, em 48 casos $(94,1 \%)$, disposições regulares, com preponderância ( 41 vêzes $-85,4 \%$ ) de espiras portadoras de dois arcos concêntricos e dois e meio excêntricos e, com menor frequência ( 7 vêzes $-14,6 \%$ ) de cólons formados por duas e meia $(5,9 \%)$, consignam enrodilhamentos extraordinários, localizando-se curvas de entrada e três de saída. Nas 3 observações complementares 
o defeito, em 1 delas, no primeiro meio lance proximal e, exibindo-se as 2 restantes totalmente irregulares. Os AA. esclarecem terem considerado, na contagem dos segmentos livres de imperfeições, os mesmos pontos de reparo sugeridos por SMITH (1955), vale dizer, tomam como limites da focada porção entérica, de um lado, secções defrontantes do primeiro e último giros, colocadas sôbre o prolongamento da linha demarcatória do limite dorsal da espira e, de outro, o centro desta última. Quanto às alças anômalas, elucidam ainda, classificam-nas segundo o critério de PAIVA \& BORELLI (1963/64), isto é, sobrepondo-as idealmente a enrodilhamentos normais. Esses AA. aduzem por fim, näo terem surpreendido, conforme demonstra a análise estatística efetuada ao nível de $5 \%$, diferenças significantes imputáveis à idade ou ao sexo, seja para os espiralamentos comuns, nas suas diferentes modalidades, seja para os incomuns.

\section{MATERIAL E METODO}

Examinamos 62 tratos cólicos, recolhidos de búfalos machos, sem raça definida, de idades variando entre dois e dois e meio anos, criados no Estado de São Paulo e abatidos no Matadouro Frigorífico Eder Ltda. (S.P.).

Logo após o sacrifício, abordando as peças pela esquerda, de modo a obter clara e direta visualização das alças, registrávamos o número de giros das espiras regulares, segundo o critério de SMITH, tendo presente as normas de PAIVA \& BORELLI, para a classificação de possíveis anomalias.

\section{RESULTADOS}

As verificações efetuadas revelaram, nos 62 casos examinados, disposições regulares do cólon convoluto; dêste total, $45(72,6 \% \pm$ $5,6)$ exibiram dois arcos de entrada e dois e meio de saida, enquanto os complementares $1^{\prime} 7(27,4 \% \pm 5,6)$, mostraram um e meio e dois lances, respectivamente centripetos e centrifugos.

\section{COMENTÄRIOS E CONCLUSÖES}

A hipótese sugerida por KOLDA, ao estudar caprinos e ovinos, da possibilidade de interferência da idade no grau de enrolamento da ansa spiralis, um dos segmentos do colon primum, homólogo do colon ascendens do homem (SUSSDORF; MARTIN; ZIETZSCHMANN; KRUGGER), não se eplica aos bubalinos, como verificaram PEDUTI, BORELLI \& BOCALLETTI, ao atestar, em recente pesquisa, a não influência dêsse fator, bem como do sexo, no volteamento do cólon em búfalos Jaffarabadi. Comparando, agora, o trabalho dêsses AA., com nossos resultados, obtidos em animais sem raça definida, pode- 
mos avaliar da possibilidade de interferência de outra variável, a raça, no espiralamento do cólon convoluto. Assim, em 51 exemplares adultos, surpreenderam, tendo presente os critérios de SMITH e PAIVA \& BORELLI, 48 alças $\left(94,1^{\prime}\right.$ 'c) perfeitas; destas, a maior parte ( 41 vêzes - 85,4\%) exibia duas curvas concêntricas e duas e meia excêntricas, configuraçōes também predominantes (45 vêzes $72,6 \%$ ) em nossa amostra; já, a disposição menos frequente $\{7$ vêzes - $14,6 c^{\prime}$ ), isto é, dois e meio giros de entrada e três de cádáda, não foi assinalada em nosso material, observando-se o inverso no torante às espiras, que descobrimos formadas por um e meio u cos centrípetos e dois centrífugos (17 vêzes - 27,4 c). Não consignamos, também, cólons portadores de imperfeições, registrados pror aquêles AA., em 3 casos $(5,9 \%)$. Finalmente, devemos aduzir, o caráter genérico dos registros de GIROLAMO, impossibilita-nos de cotejar, com os dêste A., nossos achados.

\section{SUMMARY}

The AA. observed regular patterns of the ansa spiralis in 62 post-natal buffalloes: $45(72.6 \%+5.6)$ were seen with two centripetal and two and a half centrifugal coils and, the remaining $17(27.4 \%$ \pm 5.6 ), with one and a half centripetal and two centrifugal coils.

\section{REFERENCIAS BIBLIOGRAFICAS}

GIROLAMO, A. - Rilievi comparativi sulla morfologia e sulla lunghezza dell'intestino fra Bos taurus e Bos bubalis. Nuova Vet., Bologna, 26 (1): $18-23,1950$.

KOLDA. J. - Zur Topographie des Darmes bein Schaf und bei der Leige. Z. Anat. Entwgesch., Berlim, 95: 243-269, 1931.

KRUGER, W. - Die vergleichende Entwicklungsgeschichte im Dieste der Lösung der Homologisierungsproblems an den Darm-und Gekrösakschnitten des Menschen und einiger Haussäugetiere (Hund, 5iatze, Pferd, Schwein und Wiederkäuer). T. ges. Anat., 90: 458-548, 1929.

MARTIN, P. - Lehrbuch der Anatomie der Haustiere. Bd. 2., h. 4. Stuttgart, Schickhard \& Ebner, 1912.

PAIVA, O. M. \& BORELLI, V. - Disposiçōes incomuns da ansa spiralis do cólon em bovinos azebuados. Rev. Fac.'Med. vet., São Paulo, 7 (1): 11-17, $1963 / 64$.

PEDUTI NETO, J.; BORELLI. V. \& BOCCALETTI, D. - Comportamento dell'ansa spiralis in bufali. [Trabalho apresentado à XXIV Conferência Anual da Sociedade Paulista de Medicina Veterinária. São Paulo, 1969].

SMITH, R. N. - The arrangement of the ansa spiralis of the sheep colon J. Anat., London, 89 (2): 246-249, 1955. 
SUSSDORF, M. - Homologien der Abschnitte des Dickdarms und dessen Gefässvertellung, 1901. Cit: ELLENBERGER, W. \& BAUM, H. Handbuch der vergleichenden Anatomie der Haustiere. 17 Auf. Berlin, Julius Springer, 1932.

ZIETSCHMANN, O. - Der Darmkanal der Säugetiere, ein vergleichend anatomisches und entwicklungsgeschichtliches Problem. Anat. Anz., Jena, 60: 155-172, 1925. 